
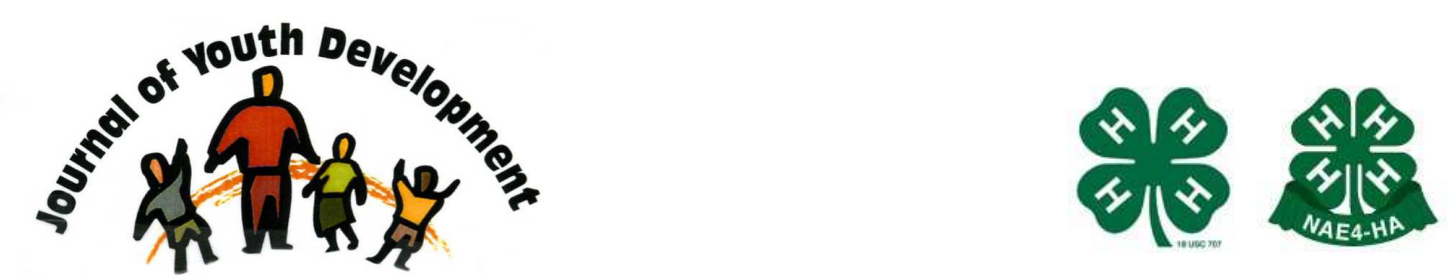

Bridging Research \& Practice

\title{
Horses and At-Risk Youth: \\ An Equine Facilitated Learning Program Focusing on Authentic Leadership Skill Development
}

\author{
Brittany L. Adams-Pope \\ College of Business \\ University of Louisville \\ Louisville, KY \\ brittany.adamspope@louisville.edu
}

Nicole L.P. Stedman

University of Florida

Gainesville, FL

nstedman@ufl.edu 


\title{
JOURNAL OF YOUTH DEVELOPMENT \\ bridging research and practice

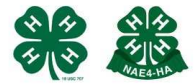

Volume 9, Number 4, Winter 2014

Article 140904PA002

\section{Horses and At-Risk Youth: \\ An Equine Facilitated Learning Program Focusing on Authentic Leadership Skill Development}

\author{
Brittany L. Adams-Pope \\ University of Louisville \\ Nicole L.P. Stedman \\ University of Florida
}

\begin{abstract}
Interesting and innovative youth development programs are important to further youth education. Programs focused on developing leadership skills in youth, specifically at-risk youth, are important when thinking of the future of our communities. The primary purpose of the study was to determine the impact of an equine facilitated, authentic leadership program on at-risk youth. Youth participated in a three-day equine facilitated learning program based on authentic leadership with focus groups conducted three days before and three days after the program. In this article, we describe the development and methodology of the program and specific implications for practice.
\end{abstract}

\section{Introduction}

John F. Kennedy (1917-1963) once said, "We must do all that we can to give our children the best in education and social upbringing-for while they are the youth of today, they shall be the leaders of tomorrow." (The Giving Child Organization, 2014). In the past decade the number of public figures, celebrities, and corporations who were involved in corruption has shown that adults in leadership positions are not always the best role models for youth (George, 2003; Whitehead, 2009). Bell and Jenkins (1993, p.47) stated the following about youth populations, "the occurrence of violence, antisocial, and destructive behaviors has been far more prevalent [in at-risk youth mentors], which has resulted in the exposed youth learning and acclimating such values, behaviors, and norms. Negative behaviors demonstrated by adults have fostered youth to engage in the same behaviors." When youth transition to adulthood, they perpetuate the same behaviors to the next generation (Hurd, Zimmerman, \& Reischl, 2011; Zimmerman, 
Steinman, \& Rowe, 1998). Unfortunately for youth in at-risk populations, positive influences may be few and far between.

As expectations have changed, the role of mentoring and socializing youth has moved from primarily a parent's duty to more of a shared role between parents, day-care workers, teachers, community members, and other youth workers. Many studies have shown (Grossman, \& Tierney, 1998; Rhodes, 2002) proper socialization requires exposure to positive and constructive behaviors, yet research has continued to demonstrate a decrease in the availability and exposure of positive adult role models and support in the lives of adolescents (Whitehead, 2009). If natural positive role models do not exist in the community or in home-life, then adolescents need to be directed elsewhere to find positive adult relationships to guide their maturation (Beck, 2005). A key indicator of this lack of positive role models is school discipline. Statistics regarding violence and discipline in schools have increased dramatically from $23 \%$ in 1990 to 74\% in 2010 (Aud, \& Hannes, 2011). Even with intervention programs, negative behaviors among at-risk youth have continued to increase (Aud, \& Hannes, 2011; Dryfoos, 1990). Scholars and practioners have determined that the lack of positive parental or adult influence and support plays a large part in the increase of youth delinquency (Flannery, Singer, Williams, \& Castro, 1998; Galambos, \& Maggs, 1991; Hurd, et al., 2011; Mahoney, \& Stattin, 2000; McHale, Crouter, \& Tucker, 2001; Pettit, Bates, Dodge, \& Meece, 1999).

Based on this research, the sample chosen for this study was middle-school aged boys living at Rodeheaver Boys Ranch. In the following paragraphs, the specifics of this research study will be explained.

\section{Rodeheaver Boys Ranch}

Rodeheaver Boys Ranch (RBR) was created by Homer Rodeheaver in 1950 to provide a "wholesome home environment with religious, educational, and vocational training for needy boys," (RBR, 2013). Many of the boys come to RBR because of parental/guardian death, desertion, divorce, parental disability, or dysfunctional home situations. Boys range in age from 6 to 18 years old. In 2010, it cost approximately $\$ 20,000$ to support one boy for one year at Rodeheaver Boys Ranch (RBR, 2010). Boys admitted to the Ranch have not been adjudicated delinquent and are required to be mentally and emotionally sound (RBR, 2013). Boys are placed at the Ranch by parents, guardians, and/or youth counselors from all over the nation. The Ranch is a not for profit 501(c) 3 charity that does not receive any federal, state, or county funding.

The participants at Rodeheaver Boys Ranch are taught authentic leadership skills using the Bill George Model (George \& Sims, 2007), which is described below.

\section{Authentic Leadership}

Authentic leadership, specifically Bill George's Model (George, \& Sims, 2007), was chosen because of its ease of understanding. The five dimensions of authentic leadership include: pursuing purpose with passion, practicing solid values, leading with heart, establishing enduring relationships, and demonstrating self-discipline (George, 2003). An authentic leader is a genuine person who is true to themselves and to what they believe. Authentic leaders are their own people, go their own way, and do not always let others guide what they do. Yet, these types of leaders are more concerned about serving others than they are about their own success or recognition. Authentic leaders are constantly looking for ways to grow personally and develop genuine connections with others and encourage trust. Finally, they are able to motivate people to high levels of performance by empowering them to lead (George, \& Sims, 
2007). This study hoped to be an effective framework for the creation of a leadership workshop for at-risk youth. The George Model (2007) provided the theoretical framework for this study and leads to a description of the equine facilitated learning model, which was the model used to educate youth on authentic leadership.

\section{Equine Facilitated Learning}

Ewing, MacDonald, Taylor, and Bowers (2007, p.60) described equine facilitated learning (EFL) as "an experiential methodology that uses a "hands-on" approach." Smith-Osborne and Selby (2010, p. 292) reported, based on recent theoretical and empirical literature, that the following psychosocial effects have been found in children and adolescents who participated in equineassisted activities (EAA): "socialization and companionship, self-esteem enhancement, improvement in personal space/boundary issues and other attachment-related problems, reduction in emotional blunting and incongruence, and improvement in meta-cognition and reflectivity," (Karol, 2007; Roberts, Bradberry, \& Williams, 2004; Rothe, Vega, Torres, Soler, \& Pazos, 2005; Saunders-Ferguson, Barnett, Culen, \& TenBroeck, 2008; Schultz, Remick-Barlow, \& Robbins, 2007). Smith-Osborne and Selby (2010, p. 292) also stated, from earlier literature, "EAA could have psychosocial benefits in the following areas, not specified by population: selfconfidence, self-esteem, self-concept, interest in learning/motivation to participate in hippotherapy, improvement in attention span/concentration/listening skills, spatial awareness, and verbal skills (MacKinnon, Noh, \& Laliberte, 1995a; MacKinnon, Noh, Lariviere, MachPhail, Allen, \& Laliberte, 1995b; Saunders-Ferguson, et al., 2008).

For the purposes of this study, researchers worked with the middle school population (ages 1215 years old) at Rodeheaver Boys Ranch. With this population, the researcher was able to create a program, using the horses already present at RBR, to teach authentic leadership based on Bill George's Model (2007). Using George's model (2007), the researcher hoped to find a new way to educate at-risk youth about authentic leadership, using equine facilitated learning. From this study, the researcher hoped to provide information in this new, innovative area that is lacking quality research.

\section{Evaluation Methodology}

\section{Purpose and Questions}

The purpose of the program was to increase the authentic leadership knowledge in participants. Specifically, the study addressed five objectives:

1. Determine the impact of the equine-facilitated authentic leadership development program on participants' perceptions of relationships,

2. Determine the impact of the equine-facilitated authentic leadership development program on participants' perceptions of self-discipline,

3. Determine the impact of the equine-facilitated authentic leadership development program on participants' perceptions of purpose,

4. Determine the impact of the equine-facilitated authentic leadership development program on participants' perceptions of values, and

5. Determine the impact of the equine-facilitated authentic leadership development program on participants' perceptions of heart.

\section{Population}

The theoretical population of this study was at-risk youth regardless of age, race, gender, or living situation. However, it is recognized that each at-risk youth has a unique situation that 
may impact and differ from the data discovered in this study. A purposive sample was chosen based on the size of the age groups and the at-risk qualifiers of the population. Boys ranged in age from 12 to 15 years old and were in grades 6-8 at a Florida middle school. There were multiple ethnicities represented with the majority being White.

\section{Evaluation Instruments}

This mixed-method case study design used participant observation, focus groups, and three quantitative questionnaires to address the objectives of the study. Focus groups were structured with researcher-developed question protocol, which were deemed acceptable by a panel of experts (see appendix). A researcher-developed questionnaire was used to determine the "Level of Comfort" participants felt around horses, which was deemed acceptable by a panel of experts (see appendix). A researcher-developed demographics survey was used to collect demographic information from participants. The final instrument was the Authentic Leadership Questionnaire developed by Avolio, Gardner, and Walumbwa (2007). The researcher developed educational activities (with horses) to teach authentic leadership knowledge and skills, described previously.

A formal review of this study by the Institutional Review Board (IRB) preceded any data collection. The IRB-02, at the University of Florida, reviews non-medical researcher proposals for ethical soundness. The IRB approved the research proposal and assigned an IRB protocol number 2012-U-0745.

\section{The Program}

The equine facilitated learning program consisted of five sessions implemented over five days, with a total of fourteen hours of participation (including lunch and breaks). The program took place at the Rodeheaver Boys Ranch Horse Unit. All participants lived at Rodeheaver Boys Ranch, but none of the participants had a direct role at the Horse Unit. The Horse Unit consisted of a barn, multiple pastures, a large round pen, and multiple horses (7-10). The round pen is where six of the activities took place and another two activities taking place in the barn. The facilitator implemented six of the eight activities, and the horse unit director facilitated two of the activities.

Assistants to the program included: the horse unit director, the assistant to the director, five older boys who were assigned to the horse unit, and a professional with a doctoral level degree in leadership education. The assistants to the program helped the facilitator with logistics and overall management of the program. At one point, the horse unit director facilitated activities, 'squeaky clean' and 'measuring,' to keep the program running quickly and smoothly. When any incidents arose, such as injury or an altercation between participants, the assistant to the director would take the boys aside and make sure they were taken care of without interrupting the program. The horse unit boys were in charge of getting the horses to and from the round pen and assisting the researcher as an "extra set of eyes" for safety. Finally, the leadership professional assisted in the administration of the questionnaires and to ensure the facilitator was assisted, when needed, with reflection questions. The leadership professional was only present on the first day of the program. All other assistants were present all three days of the program.

Each of the sessions covered a different aspect of George's Authentic Leadership Model (2003): relationships, self-discipline, purpose, values, and heart. The activities were determined by the researcher and were collected from multiple Equine Facilitated Learning guides (EAGALA, 2012; Mandrell, \& Mandrell, 2008). The established activities were selected for their fit to the desired 
outcome. The manuals used were titled: Fundamentals of EAGALA Model Practice Untraining Manual, Seventh Edition (EAGALA, 2012) and Champions Curriculum-EAP Group Curriculum for At-Risk Adolescents, Third Edition (Mandrell, \& Mandrell, 2008).

Before participants were introduced to the horses, the horse unit director completed a safety demonstration with each participant. During this safety demonstration, participants were informed about how to safely work with horses, what the dangers were, where the danger zones for horses were, and how to interact properly with the horses while keeping safety in mind. The sessions were videotaped to allow the researcher to review each session for program evaluation purposes. Each session is covered in depth in the following sections.

It is important to note that activities involving horses should not be done by practioners without previous horse experience and/or training. It is also important to have multiple assistants in the ring and on hand in the case of an emergency and to act as supplementary "eyes" for the safety of participants and horses.

\section{Activities}

Each activity was created using the EAGALA manual (EAGALA, 2012) or the Champions curriculum (Mandrell, \& Mandrell, 2008). See Appendix for a timeline of activities and complete activity descriptions.

\section{"Catch and Halter"}

This activity was chosen to display relationships based on the interactions with the horses and the partners. The facilitator believed that once the boys were tasked with catching and haltering a horse, the act of creating a relationship, with the horse and their partner, would develop. Some horses would be easy to catch while others would be difficult. Each event would give the facilitator opportunities to solicit reflection based on relationships and the events.

\section{"Extended Appendages"}

This activity was chosen to display relationships based on the interactions with the horses and the groups. The facilitator believed that during the activity, participants would be required to form relationships with their group or risk not completing the task. The facilitator knew the horses may be difficult to catch because of the fact that four boys were linked and coming towards them. This may be scary to the horse. This fear response could result in the horse walking or running away from the group, this action would require the boys to practice teamwork and relationship building to solve the problem and complete the task. Also, having to rely on one another for direction helped to build a relationship between the boys.

\section{"Life's Little Obstacles"}

This activity was chosen to display self-discipline based on the interactions with the horses, temptations, rules, and group members. The facilitator believed that during the activity, the boys would see the horses choosing feed or another temptation over listening to instruction. The facilitator would then use the horses' distraction as a base for reflection questions to solicit the links between the horses' temptations and the boys' temptations at home or school, etc.

\section{"Circularelations"}

This activity was chosen to display purpose based on the interactions with the horses, conflicting instructions, rules, the other group, and group members. The facilitator believed that when the boys received conflicting instruction, it would immediately create conflict between the 
groups. Instead of immediately dissipating the conflict, the facilitator would allow the boys to disagree a bit to solicit a request for help. Once the boys asked for help, the facilitator would use that time to ask about each group's 'purpose' and lead the reflection from there.

\section{"Creactivity"}

This activity was chosen to display value building based on the interactions with the horses, friendly competition, the other group, and group members. The facilitator believed that during the activity, providing a competition would encourage the boys to determine if they valued winning or succeeding at a task more. Creating this internal conflict between creating a task so difficult no one could do it or winning the game would provide for good reflection on the thought process. This reflection would allow the boys to draw the link between having differing values amongst the same goals.

\section{"Squeaky Clean"}

This activity was chosen to display value building based on the interactions with the horses, partner interaction, and determining the meaning of "squeaky clean." The facilitator believed that having the pairs agree on the determination of "squeaky clean" would solicit a discussion about why the boys may not agree. This discussion would lead to a reflection about how people's ideas or values of things may be different but neither is necessarily wrong.

\section{"Fear Factor"}

This activity was chosen to display heart based on the interactions with the horses, the element of fear for the horse, and group interaction. The participants had become attached to the horses so the facilitator believed that soliciting a fear response from the horse would solicit empathy in the boys. The facilitator believed that once the horse was scared, the boys would ask that the assistants stop scaring the horse by taking the bag away. Once this request was made, the facilitator would link the fear in the horse and the want for it to stop, to the boys' daily interactions; showing the boys that empathy and heart happen all around them.

\section{"Measuring"}

This activity was chosen to display heart based on the interactions with the horses, the ordering activity based on size, and group interaction. The facilitator believed that having the boys specifically order the horses by size would solicit discussion about what makes one horse bigger or smaller than the others. During this discussion the facilitator would use the actual measurements to show that size can be deceiving. Once the actual sizes were given, the facilitator would solicit reflection about how this can happen in day to day life, showing the boys that it is hard to determine one thing as being bigger, smaller, better, or worse, than another thing without proper investigation.

\section{Evaluation Results}

Overall, the focus groups showed an increase in knowledge of most of the elements of the George Model (2007). The depths of thought increased from preprogram focus groups to post program focus groups but it is not definitive that the participants understood purpose, values, or heart, completely.

Programmatically, the focus groups ran fairly well. For the age group, 12-15 years old, the conversation was as expected. The decision to do focus groups, instead of individual interviews, was to encourage a conversation, not just a question and answer session. There were two groups of seven to nine boys each and this may have been too many boys in one session. The 
boys would sometimes answer based off each other saying, "yeah, that's what I think too," and at other times they would discourage answers from the quieter boys in the group saying, "that's stupid" or "that's not even real." When working with this age group in the future, it is suggested to make the focus groups smaller, four to five youth maximum.

When going through the transcriptions, there was not as rich of detail as anticipated. The answers were very short, one word or a short sentence, not very much elaboration on each topic. The age group of the participants may have contributed to the lack of detail during the focus groups. The field notes were imperative as there was a lot the transcriptions did not catch due to background noise and crosstalk. It was also important that that the researcher was present during all sessions to have memory to reflect on about how the boys were communicating, verbally and nonverbally.

The similarities and differences in themes from the focus groups helped explain why there was a change in the preprogram ALQ and the post program ALQ data. The participants showed knowledge on a basic level, preprogram, regarding the four components of the Authentic Leadership Questionnaire [ALQ] (Avolio, et al., 2007): transparency, ethical/moral, balanced processing, and self-awareness. This introductory knowledge may have accounted for the minimal change in the mean scores from the ALQ data.

\section{Conclusions}

A holistic review of the results from both segments of this study demonstrated the program was successful in regards to the objectives of educating youth about authentic leadership. The following conclusions were drawn with the understanding that due to the selection process of participants, a purposive sample of middle-school age boys from Rodeheaver Boys Ranch, the generalizability of the conclusions and recommendations should be carefully considered.

The participants showed knowledge on a basic level, preprogram, regarding the four components of the Authentic Leadership Questionnaire (ALQ) (Avolio, et al., 2007): transparency, ethical/moral, balanced processing, and self-awareness. This introductory knowledge may have accounted for the small amount of change from pre to post program. Also, Barnett (2013), an expert in youth development, found a lack of initial learning gains during at-risk programming when evaluating post program. She (2013) found, during her many program implementations with the Children, Youth, and Families At-Risk Program (CYFAR), atrisk youth need time to process the information they receive during programming, so evaluating immediately after a program may lead to skewed or no results. With this in mind, the researcher consulted with the horse unit director to determine if the participants showed an increase in leadership overall. The horse unit director reported positive changes in the boys and stated they still talk about the program and how much fun they had, five months post program.

The fact that the program focused on the five dimensions of the George (2007) model and the ALQ focused on four different dimensions must be taken into account when reviewing the quantitative data. Developing a program that focuses on the four dimensions of the ALQ would make the results from the ALQ questionnaire more relatable. In regard to the ALQ, previous research (Avolio, et al., 2007; Gardner, Avolio, \& Walumbwa, 2005b; Gardner, \& Schermerhorn, 2004) has focused on adults. The questions in the ALQ are geared more towards adults; this leads the researcher to believe that some of the questions may have been too advanced or abstract for the participants in this study. Future studies could use a modified ALQ created for 
youth. Vice versa, creating a questionnaire/ instrument to test the five dimensions of the George (2007) model would make evaluating the program more effective.

\section{Recommendations for Practice}

Based on the results of this study, there are several recommendations for programs that seek to teach authentic leadership skills using equine facilitated learning methods. While this study was focused on the at-risk population, specifically Rodeheaver Boys Ranch, these recommendations may be applied to other programs of similar function and structure.

It is recommended to perform a pre and post program questionnaire based on the dimensions being taught during the program to determine the impact the program may or may not have on the participants. Collecting data regarding the ALQ and Level of Comfort was very important in determining the efficacy of the program. It is also recommended to work with smaller groups at a time. Sixteen, middle-school age boys was too many for this program; the participants not actively engaged with the activity were left to their own devices. It is suggested to maintain small groups, preferably a maximum of four to five at one time. It may be beneficial for older age groups to observe others during activity, but that is inconclusive due to the population of this study. Having multiple program assistants to help with the logistics of multiple horses is recommended. The facilitator should be processing the events consistently so having someone to exchange horses and retrieve props is advised. One area of interest was that the boys filling out the questionnaires (preprogram) were more worried about getting to interact with the horses than filling out the questionnaires. The distractions may have caused skewed results for the quantitative data. In hindsight, it is suggested to have a specified, focused time for the questionnaires to be filled out, away from distraction, if questionnaires are utilized.

In regards to the activities, it is suggested to adapt the exercises based on attentiveness of the participants. If the facilitator seems to lose the participant focus, it may be time to move on to the next activity. After lunch on the second day, the participants were very inattentive. The lack of focus and attention is a reason it is suggested to have smaller groups so there are not observers, only active participants. Programmatically, it is suggested to work in shorted time periods with younger age groups. Eight hours of programming was too long and the quality of the program was negatively impacted. For the 'purpose' dimension, the results from the focus groups showed a decrease in self-perception. With this in mind, it is advised to revisit the efficacy of the particular activity associated with that session. It is also recommended to get feedback from the participants, within reason. Learning participant expectations may help the facilitator create a more effective program. Equine facilitated programs can be implemented in various lengths. If a program is brief and does not consist of in-depth theories, it could be implemented in one afternoon. If the program, such as this, covers a more in depth theory, it can be implemented over the course of days or even weeks. When developing this particular program, the researcher created outlines for 3-day programs to 7-week programs and much iteration in between. Depending on the time frame and the depth of theory involved, future programmers can adapt the program length as needed.

This study can be categorized as a life-skill development program or a prevention program for at-risk youth. Providing youth with leadership skills is important in life-skill development and may also help prevent these pre-adjudicated youth from offending in the future. In regard to risk and protective factors, this program is a protective factor, in that it provides youth, skills necessary to succeed in the future and overcome their many risk factors. In the future, youth workers, program developers, educators, and many other professional may use equine 
facilitated learning programs for life-skill development, prevention, intervention, and/or diversion programs. While logistically it is difficult, an equine facilitated learning program can be used in rural and urban settings. Gang intervention and prevention programs could benefit from this type of program because it takes the participants out of their comfort zone and provides the large, physical attributes of the horse as facilitators. Instead of being able to "push" the facilitator around, more aggressive participants have to act in response to the horses. Other populations that could benefit from these types of programs include: adults, corporations, youth organizations, academia, and many others. The adaptability of equine facilitated learning programs lends itself to work in many situations, with proper training.

\section{References}

Aud, S., \& Hannes, G. (Eds.) (2011). The Condition of Education 2011 in Brief (NCES 2011034). U.S. Department of Education, National Center for Education Statistics. Washington, DC: U.S. Government Printing Office.

Avolio, B.J., Gardner, W.L., \& Walumbwa, F.O. (2007). Authentic leadership questionnaire. Mind Garden, Inc.

Barnett, R. (2013). Personal communication.

Beck, L.E. (2005). Infants, children, and adolescents (5th ed.). Boston, MA: Pearson Education, Inc.

Bell, C. \& Jenkins. E. (1993). Community violence and children on Chicago's south side. Psychiatry, 56, 46-54.

Dryfoos, J.G. (1990). Adolescents at risk: Prevalence and prevention. Oxford University Press on Demand.

Equine Growth and Learning Association (EAGALA). (2012). Fundamentals of EAGALA Model Practice Untraining Manual, Seventh Edition.

Ewing, C.A., MacDonald, P.M., Taylor, M., \& Bowers, M.J. (2007). Equine-facilitated learning for youths with severe emotional disorders: A quantitative and qualitative study. Child \& Youth Care Forum, 36, 59-72.

Flannery, D.J., Singer, M., Williams, L., \& Castro, P. (1998). Adolescent violence exposure and victimization at home: Coping and psychological trauma symptoms. International Review of Victimology, 6, 29-48.

Flannery, D.J., Singer, M., Williams, L., \& Castro, P. (1998). Adolescent violence exposure and victimization at home: Coping and psychological trauma symptoms. International Review of Victimology, 6, 29-48.

Galambos, N.L., \& Maggs, J.L. (1991). Out-of-school care of young adolescents and selfreported behavior. Developmental Psychology, 27, 644-655 
Gardner, W.L., Avolio, B.J., Walumbwa, F.O. (2005b). Authentic leadership development: Emerging trends and future directions. In W.L. Gardner, B.J. Avolio, \& F.O. Walumbwa (Eds), Authentic leadership theory and practice: Origins, effects, and development (pp. 183-202). Oxford: Elsevier Science.

Gardner, W.L., \& Schermerhorn, J.R. (2004). Unleashing individual potential: Performance gains through positive organizational behavior and authentic leadership. Organizational Dynamics, 33(3), 270-281. doi:10.1016/j.orgdyn.2004.06.004

George, B. (2003). Authentic leadership: Rediscovering the secrets to creating lasting value. San Francisco: Jossey-Bass.

George, B., \& Sims, P. (2007). True north: Discover your authentic leadership. San Francisco, CA US: Jossey-Bass. Retrieved from https://search.ebscohost.com/login.aspx?direct=true\&db=psyh\&AN=2007-05744000\&site=ehost-live

Grossman, J.B., \& Tierney, J.P. (1998). Does mentoring work? An impact study of the Big Brothers Big Sisters program. Evaluation review, 22(3), 403-426.

Hurd, N.M., Zimmerman, M.A., \& Reischl, T.M. (2011). Role Model Behavior and Youth Violence: A Study of Positive and Negative Effects. Journal of Early Adolescence, 31(2), 323354.

Karol, J. (2007). Applying a traditional individual psycholtherapy model to equine-facilitated psychotherapy (EFP): Theory and method. Clinical Child Pscyhology and Psychiatry, 12, 77-90.

Mackinnon, J.R., Noh, S., \& Laliberte, D. (1995a). Therapeutic horseback riding: A review of literature. Physical and Occumpational Therapy in Pediatrics, 15, 1-15.

Mackinnon, J.R., Noh, S., Lariviere, J., MachPhail, A., Allen, D.E., \& Laliberte, D. (1995b). A study of the effects of horseback riding for children with cerebral palsy. Physical and Occupational Therapy in Pediatrics. 15, 17-34.

Mahoney, J.L., \& Stattin, H. (2000). Leisure activities and adolescent antisocial behavior: The role of structure and social context. Journal of adolescence, 23(2), 113-127.

Mandrell, P. \& Mandrell, R. (2008). Champions Curriculum-EAP Group Curriculum for At-Risk Adolescents, Third Edition. Equine Assisted Growth and Learning Association.

McHale, S.M., Crouter, A.C., \& Tucker, C.J. (2001). Free-time activities in middle childhood: Links with adjustment in early adolescence. Child development, 72(6), 1764-1778.

Pettit, G.S., Bates, J.E., Dodge, K.A., \& Meece, D.W. (1999). The Impact of After-School Peer Contact on Early Adolescent Externalizing Problems Is Moderated by Parental Monitoring, Perceived Neighborhood Safety, and Prior Adjustment. Child Development, 70(3), 768-778.

Rhodes, J.E. (2002). Stand by me: The risks and rewards of mentoring today's youth. Cambridge, MA: Harvard University Press. 
Roberts, F., Bradberry, J., \& Williams, C., (2004). Equine-facilitated psychotherapy benefits students and children. Holistic Nursing Practice, 18, 32-35.

Rodeheaver Boys Ranch (RBR). (2010). The Ranch Wrangler, October, 2010. Retrieved on March 24, 2013 from http://www.rbr.org/pdfs/Wrangler\%20Magazine\%202010-1.pdf

Rodeheaver Boys Ranch (RBR). (2013). Retrieved on January 11, 2013 from http://www.rbr.org/

Rothe, E.Q., Vega, B.J., Torres, R.M., Soler, S.M.C., \& Pazos, R.M.M. (2005). From kids and horses: Equine facilitated psychotherapy for children. International Journal of Clinical and Health Psychology, 5, 373-383.

Saunders-Ferguson, K., Barnett, R.V., Culen, G., \& TenBroeck, S. (2008). Self-esteem assessment of adolescents involved in horsemanship activities. Journal of Extension, 46(2).

Schultz, P.N., Remick-Barlow, G.G., \& Robbins, L. (2007). Equine-assisted psychotherapy: A mental health promotion/intervention modality for children who have experienced intra-family violence. Healthy and Social Care in the Community, 15, 265-271

Smith-Osborne, A., \& Selby, A. (2010). Implications of the literature on equine-assisted activities for use as a complementary intervention in social work practice with children and adolescents. Child and Adolescent Social Work Journal, 27(4), 291-307.

Whitehead, G. (2009). Adolescent leadership development: Building a case for an authenticity framework. Educational Management Administration \& Leadership, 376), 847-872. Retrieved from http://dx.doi.org/10.1177/1741143209345441

Zimmerman, M.A., Steinman, K.J., \& Rowe, K.J. (1998). Violence among urban African American adolescents: The protective effects of parental support. In X.B. Arriaga \& S. Oskamp (Eds.), Addressing community problems: Psychological research and interventions (pp. 78-103). Thousand Oaks, CA: Sage.

(c) Copyright of Journal of Youth Development $~$ Bridging Research and Practice. Content may not be copied or emailed to multiple sites or posted to a listserv without copyright holder's express written permission. Contact Editor at: patricia.dawson@oregonstate.edu for details. However, users may print, download or email articles for individual use.

ISSN 2325-4009 (Print); ISSN 2325-4017 (Online) 